\title{
Derleme
}

\section{Anesteziyolog Bakış Açısından Atriyal Fibrilasyon}

\author{
Hanife KARAKAYA KABUKÇU, Nursel ŞAHİN, Tülin AYDOĞDU TİTiz
}

\section{$\ddot{0 ̈ Z}$}

\begin{abstract}
Atriyal fibrilasyon en sık görülen kardiyak aritmidir. Anestezistler preoperatif değerlendirmenin yanı sıra, hastalarda intraoperatif ve postoperatif yeni basslayan veya başlangıç zamanı bilinmeyen AF ile karşı karşıya kalmaktadır. AF'lu hastalarda, hemodinamik stabiliteyi korumak ve komplikasyonları önlemek deneyim gerektirir.
\end{abstract}

Bu derlemede, AF sınflandırılması, intraoperatif tedavisi ve AF nedeniyle antikoagülan kullanan hastalarda anestezi yönetimi sunulmuştur.

Anahtar kelimeler: atriyal fibrilasyon, anestezi, antikoagülasyon
ABSTRACT

Atrial Fibrillation from Anesthesiologist's Perspective

Atrial fibrillation $(A F)$ is the most frequent cardiac arrhythmia. In addition to preoperative evaluation of patients, anesthesiologists are faced with a newly developed AF with unknown time of onset. To maintain hemodynamic stability and to avoid complications in patients with AF require experience

This review presents AF classification, and its intraoperative treatment anesthetic management of patients taking anticoagulants due to AF.

Keywords: atrial fibrillation, anesthesia, anticoagulation

\section{GíRiș}

Atriyal fibrilasyon (AF) en sık görülen kardiyak aritmidir, atriyal miyositlerdeki elektiriksel aktivitenin bozukluğu ile oluşur. AF serebral tromboemboli zemininde inme ve diğer tromboembolik olaylar, sol ventrikül fonksiyon bozukluğu, kalp yetmezliği gibi mortaliteyi artıran ciddi komplikasyonlar ile birliktedir. Ayrıca hastaneye yatış oranında artma, yaşam kalitesinin bozulması ve egzersiz kapasitesinin azalması gibi nedenlerle morbiditeyi etkilemektedir ${ }^{[1]}$. AF genel popülasyonun \%1-2'sinde ve görülme sıklığ $40-50$ yaş aralığındadır. Yaşla birlikte artmakta ve 80 yaşında \% 5-15 oranına ulaşmaktadır ${ }^{[2-6]}$. Erkekler kadinlardan daha fazla etkilenmektedir ${ }^{[7]}$.

EKG'de P dalgalarının yokluğu ve düzensiz RR aralı$\breve{g}$ 1 saptanması ile AF tanısı konur. Aritminin başlangıç

Alındığı tarih: 28.09.2016

Kabul tarihi: 11.01.2017

Akdeniz Üniversitesi Tıp Fakültesi, Anesteziyoloji ve Reanimasyon Anabilim Dalı

Yazışma adresi: Doç. Dr. Hanife Karakaya Kabukçu, Akdeniz Üniversitesi Tip Fakültesi, Anesteziyoloji ve Reanimasyon Anabilim Dalı, Dumlupınar Kampüsü 07070 Antalya

e-mail: hanifekabukcu@akdeniz.edu.tr ve seyrine göre paroksismal, ısrarcı ve kalıcı olmak üzere üç sekilde sınıflandırılır. Paroksismal AF 48 saat içinde genellikle kendiliğinden düzelir. Israrcı AF 1 haftadan 1 yıla kadar sürebilir, kendiliğinden düzelmez medikal veya doğru akım (DC) kardiyoversiyon ile sinüs ritmine döndürülebilir (Tablo 1). Kalıcı AF'de medikal veya kardiyoversiyon ile sinüs ritmine dönüş olası olmaz ${ }^{[1,89]}$. AF tanısı EKG ile kolaylıkla konmasına rağmen, birçok hastada asemptomatiktir. Komplikasyonlar gelişene kadar tanı konamayabilir. AF nedeni kardiyovasküler veya değildir. Örneğin, geçirilmiş miyokard infarktüsü, kardiyomiyopati, hipertansiyon, kapak hastalıkları ve kalp yetmezliği kardiyovasküler nedenlerdir. Diyabet, obezite, alkol, hipertiroidi, KOAH ve diğer metabolik bozukluklar ise diğer AF nedenleridir ${ }^{[8,10]}$.

Preoperatif AF tanısı alan hastada anestezist, semptomları hafifletme, hemodinamik stabiliteyi devam ettirme ve kardiyopulmoner komplikasyonları önlemeye odaklanmalıdır. Cerrah ile birlikte anestezist, cerrahiye devam kararına varmadan önce kalp açısından temel laboratuvar ve görüntüleme tetkiklerinin gerekliliğine karar vermelidiir ${ }^{[1,11]}$. 
Tablo 1. İlk defa tanı konan atriyal fibrilasyonun atağ ${ }^{[1]}$.

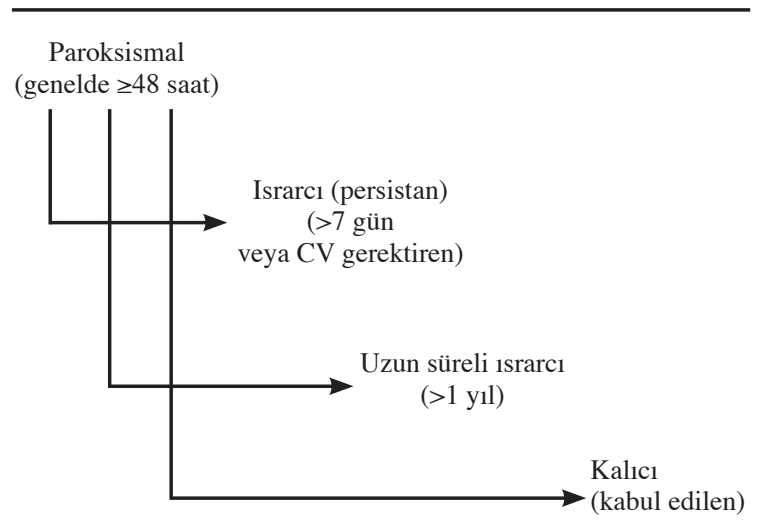

\section{Ekokardiyografi}

Ekokardiyografi AF'a neden olan hastalıkların bazılarına tanı konmasına (mitral darlığı, perikardit vb.) katkıda bulunur. Ayrıca AF'nun komplikasyonu olarak gelişen sol ventrikül ejeksiyon fraksiyon düşüklüğü ve kalp yetmezliği tanısı konmasını kolaylaştıır.

Kırk sekiz saatten uzun süren aritmide intrakardiyak trombüs oluşma riski yüksektir. Transözefagial ekokardiyografi (TÖE) ile kalbin sol taraf anatomik yapısını değerlendirme transtorasik ekokardiyografiye göre daha üstündür. TÖE kardiyak kökenli embolinin tanınmasında duyarlı ve özgün bir tekniktir ve AF'lu hastaların inme riskini sınıflandırılmasında da kullanılır. Kardiyoversiyon öncesi TÖE yapılan hastalarda sol atriyum ve sol atriyum apendiksinde trombus sıklı ̆ı $\%$-15 olarak saptanmıştır ${ }^{[1,9]}$.

\section{ATRIYYAL FİBRILASYONDA TEDAVI YAKLAŞIMI}

Hastaları introperatif daha iyi tedavi etmek için, AF sınıflandırılması için bir rehber kullanmalıdır. Tedavide amaç; yüksek ve düzensiz ventrikül atımı zemininde gelişebilecek düşük kalp debisini ve kalp yetmezliğini, sol atriyum apendikste trombus oluşumu ve buna bağlı gelişebilecek tromboembolik komplikasyonları önlemektir.

AF'lu hastalarda ilk önce hemodinamik veriler değerlendirilir, yaşamı tehdit eden ve semptomatik hastalarda tedavinin amacı, stabiliteyi sağlamaktır. Yüksek ventrikül hızlı $\mathrm{AF}$ ile hemodinamik stabilitenin bozulması acil kardiyoversiyon gerektiren bir durumdur. Direkt transtorasik kardiyoversiyon sinüs ritmine çevirmede iyi bilinen bir tedavi yöntemidir. Yüksek enerji şoklarının uygulandığı kardiyoversiyonda ağrı ve rahatsızlık olacağı için anestezi gerekmektedir. Ancak hemodinami stabil ise tedavide kalp hızının kontrolü yeterli olur ${ }^{[1,12,13]}$.

\section{Hiz kontrolü}

AF süresi bilinmiyor veya 48 saatten daha uzun süredir mevcut ise yeterli antikoagülasyon sağlanana kadar kalp hızının kontrolü gerekmektedir. Hız kontrolünde amaç aritmiyi sinüs ritmine döndürmeden ventrikül hızını kontrol etmektir ve bu tedavi başlıca hız-kontrol ilaçlarını kullanarak sağlanır. Bu ilaçların sıklıkla hipotansiyon, bradikardi, kalp bloğu ve kalp

Tablo 2. Hız kontrolünde kullanılan ilaçlar ${ }^{[1]}$.

\begin{tabular}{|c|c|c|c|}
\hline Beta Blokerler & Esmolol & İntravenöz doz & Yan etkiler \\
\hline & & Yükleme dozu 0,5 mg/kg İdame 0.06-0.2 mg/kg/dk. & $\begin{array}{l}\text { Hipotansiyon, bradikardi kalp bloğu, } \\
\text { bronkospazm, kalp yetmezliği }\end{array}$ \\
\hline & Metoprolol & $2,5-5 \mathrm{mg} \mathrm{2-5} \mathrm{dk}$ & \\
\hline & Propranolol & Bolus $0.15 \mathrm{mg} / \mathrm{kg}$ & \\
\hline \multirow[t]{2}{*}{ Kalsiyum kanal antagonistleri } & Diltiazem & $\begin{array}{l}\text { Yükleme: } 0.25 \mathrm{mg} / \mathrm{kg} \\
\text { İdame: } 5-15 \mathrm{mg} / \mathrm{st}\end{array}$ & \\
\hline & Verapamil & Bolus: $0.075-0.15 \mathrm{mg} / \mathrm{kg} 2 \mathrm{dk}$. uzun sürede & \\
\hline Amiodarone & & $\begin{array}{l}\text { Yükleme: } 150 \mathrm{mg} 10 \mathrm{dk} \text {. uzun sürede } \\
\text { İdame: } 0.5-1 \mathrm{mg} / \mathrm{dk} \text {. }\end{array}$ & $\begin{array}{l}\text { Hipotansiyon, bradikardi, kalp bloğu, } \\
\text { pulmoner fibrozis, tiroid ve hepatik } \\
\text { disfonksiyon }\end{array}$ \\
\hline Dronedarone & & $\begin{array}{l}\text { Uygun değil } 400 \mathrm{mg} \text { oral } \\
\text { Kalıcı AF'de önerilmez }\end{array}$ & \\
\hline
\end{tabular}


yetmezliği gibi yan etkileri bulunmaktadır ${ }^{[14]}$. Bu yan etkiler genel anestezi altındaki hastaların hemodinamisini bozabilir. Hız kontrol ilaçlarının başlangıç dozlarının düşük olması ve sürekli infüzyon olarak uygulanması yan etki sıklığını azaltabilir. Kalp hızının $<100$ atım/dk. seviyelerinde korunması anestezistler için kolay olabilir ${ }^{[1,9]}$. Hız kontrolünde kullanılan ilaçlar Tablo 2'de belirtilmiştir.

\section{Ritm kontrolü}

Yeni başlayan AF' da hastaların çoğu kendiliğinden sinüs ritmine dönerler. Eğer sinüs ritmine dönmemişse farmakolojik veya elektriksel kardiyoversiyon düşünülmelidir. Kullanılan antiaritmik ilaçların uzun dönem yan etkilerine karşı dikkatli olunmalıdır. Ventrikül hız kontrolüne rağmen, hâlâ semptomları (kalp yetmezliği, hipotansiyon ve anjina) devam eden hastaların sinüs ritmine çevrilmesi uygundur. Genellikle, kardiyoversiyonda antiaritmik ilaçlardan daha etkili ve hızlı yanıt alınır. Başarılı kardiyoversiyon sonrası, uzun süreli ilaç tedavisi AF yinelemesini önlemek için gerekebilir, amiodaron uygun bir seçenektir ${ }^{[1,9,14]}$.

Yeni başlayan postoperatif AF (POAF) dört basamakta tedavi edilir. Bunlar, AF'na eşlik eden hipoksi, elektrolit bozukluğu gibi yandaş hastalıkların tedavisi, aritmi tedavisi, altta yatan sepsis gibi postoperatif komplikasyonların ve antikoagülan tedavisidir. POAF, bazı hastalarda kendiliğinden düzelebilir, geçici olduğu için antiaritmik ve antikoagülan tedavisine gerek duyulmaz. Kendiliğinden düzelmeyen hastalarda antiaritmik ilaç olarak en çok kullanılan amiodarondur. Amiodaronun etkisi geç başlar. Ciddi akciğer hastalığı bulunan ve pnömonektomi geçiren hastalarda dikkatli kullanılmalıdır. Toksisite gelişimi ileri yaş ve uzun süreli kullanıma bağlı olmasına rağmen, yüksek doz amiodaron sonrasi akut pulmoner toksisitede bildirilmiştir. AF 24 saat içinde sinus ritmine döndürülemez ise o zaman antikoagülan tedavide başlanmalıdır ${ }^{[1,9]}$.

AF için yeni bir tedavi yöntemi olan pulmoner ven orifislerinin kateter ablasyonu ile inme ve ölüm oranlarının azaldığı gösterilmiştir.

\section{ATRIYYL FİBRILASYONU OLAN HASTA- LARDA ANESTEZİ ve CERRAHİ ILE İLIŞKİLI ÖZEL DURUMLAR}

\section{A) Epidural Anestezi}

Bir cerrahi hastalıktan dolayı oluşan ağrı, anksiyete ve korkunun oluşturduğu yüksek adrenerjik tonus AF gelişimini tetikleyebilir. Bununla birlikte, adrenerjik ve vagal ilaçlarında AF gelişimine etkisi vardır. Epidural anestezi preoperatif AF gelişimi için direkt risk faktörü olarak görünmemesine rağmen, rejional anestezide kullanılan lokal anestezikler ve vazopressörler adrenerjik ve vagal tonusu değiştirebilirler. Rogers ve ark.'nın ${ }^{[15]}$ olgu sunumunda, epidural anestezi sırasında gelişen hipotansiyon ve bradikardi tedavisinde uygulanan efedrin ve fenilefrin sonrası gelişen AF nedeniyle operasyonun ertelendiği ve metoprolol ile hastanın sinüs ritmine döndüğ ü rapor edilmiştir.

Aleksin ve ark.$^{[16]}$ toraks cerrahisinde retrospektif 472 hasta üzerinde yaptıkları çalışmada POAF görülme sıklığı araştırılmıştır. Genel anestezi ile birlikte interkostal blok uygulanan gruba göre genel anestezi ile birlikte torakal epidural anestezi uygulanan grupta, POAF daha az görülmüştür.

Bakhtiary ve ark. ${ }^{[17]}$ of pump koroner arter baypas cerrahisinde genel anestezinin yanı sıra torakal epidural anestezi uygulamasının endojen epinefrin düzeylerini düşürdüğünü ve intraoperatif $\mathrm{AF}$ ve aritmi gelişimini azaltı̆̆ını görmüşlerdir.

AF nedeniyle antikoagulan tedavi alan hastalarda rejional anestezi uygulamasına bağlı kanama riski vardır. Klavuzlar, antikoagülanların kesilmesi, nöroaksiyal işlemlerin yapılması ve ilaçların yine başlanması için gereken güvenlik aralığ 1 için farklı önerilerde bulunmaktadır ${ }^{[15]}$. Antikoagülan ilaç nöroaksiyal işlemlerden veya epidural kateter çekildikten sonra çoğu hastada 24-48 saat içinde yeniden başlanabilir. Fakat ilacın pik etki zamanı minimum 24 saattir, venöz tromboemboli ve inme riski yüksek hastalarda bu ilaçlar daha erken alınabilir. Yeni antiplatelet ilaçlardan prasugrel ve tikagrelor nöroaksiyal enjeksiyondan 5-7 gün önce kesilmeli, işlemden 24 saat sonra tekrar başlanmalıdır ${ }^{[18]}$. Antiplatelet tedavi alan hastalarda eğer uygunsa periferik sinir blokları uygu- 
lanabilir. USG eşliğinde damar yapılarının görüntülenmesi ile intravasküler enjeksiyon olasılığı azalır. Ancak lumbal pleksus ve paravertebral bloklarda kanama olasılığı olduğundan santral bloklardaki köprü yöntemi önerilmektedir ${ }^{[18]}$. Köprü tedavisi; cerrahi veya invaziv grişimler için oral antikoagülanın geçici olarak kesilmesi ve kısa etkili antikoagülanların örneğin düşük molekül ağırlıklı heparin veya fraksiyone olmayan heparinin kullanılmasıdır.

\section{B) İntraoperatif antikoagülan tedavi}

\section{B1-Yeni başlayan postoperatif AF (POAF)}

Antikoagülanlar çeşitli klinik durumlarda, venöz tromboemboli tedavisinde, akut koroner sendromda ve AF'da inmeyi önlemek için kullanılır ${ }^{[18]}$. Postoperatif süreçte kanama riskinin artışı ve POAF'ın çoğunlukla 24 saatten daha kısa sürmesi ve kendiliğinden geçmesi tedavi dozunda heparin kullanımını gerektirmez. Genel bir kural olarak 24-48 saatten uzun sürenlerde ve sık tekrar eden AF ataklarında tedavi edici dozda antikoagülan verilir. Yüksek riskli hastalarda sinüs ritmine döndükten sonra yaklaşık 4 hafta antikoagülan tedaviye devam edilmesi önerilmektedir ${ }^{[8]}$.

\section{B2-Uzun süreli oral antikoagülan alan AF hastalart}

$\mathrm{Bu}$ hastalarda elektif invaziv ve cerrahi işlemler için tedavinin kesilmesi gerekebilir. Klavuzlar da intraoperatif tromboemboli ve kanama riskine göre karar verilmesi önerilir. Öncelikle inme, cerrahi ve hasta ile ilgili risk faktörler değerlendirilir. Anestezistler için ilk sorgulama, oral antikoagülan verilmesinde herhangi bir değişiklik yapılmadan ameliyatın yapılıp yapılamayacağıdır ${ }^{[8]}$. Yüzeyel cerrahi işlemlerde antikoagülan kesilmeden işlem yapılabilir. Tromboemboli riskinin düşük olduğu olgularda normal hemostaz gerektiren işlemlerde oral antikoagülan tedavi kesilerek gerekli girişim yapılabilir (Tablo 3 ve 4) .Normal hemostaz gerektiren ve tromboemboli riskinin yüksek olması nedeni ile antikoagülan tedavinin kesilemeyeceği durumlarda kullanılır ${ }^{[19]}$.

\section{B3-Yeni oral antikoagülan kullanan hastalarda anestezi ve cerrahi}

Vitamin K antagonistleri AF'lu hastalarda inme riskini anlamlı olarak azaltır ${ }^{[8]}$. Dabigatran, rivaroksaban ve apiksaban gibi yeni oral antikoagülanlar kapak hastalığı dışı nedenli AF hastalarında vitamin K antagonistlerine alternatif olarak kullanılmaktadır ${ }^{[8]}$. Yeni oral antikoagülan kullanan hastalarda cerrahi işlemler için köprüleme tedavisi önerilmekte ve bu ilaçlar postoperatif erken dönemde kanama riski ve antagonize edilememesi nedeniyle verilmemelidirler ${ }^{[8]}$.

Dabigatran trombin inhibitörü, rivaroksaban ve apiksaban faktör Xa inhibitörüdür. Dabigatran etki başlangıcı hızlıdırve koagülasyon monitörizasyonu gerektirmez. Dabigatran kullanımıyla trombin zamanı ve aktive edilmiş parsiyel tromboplastin zamanı uzar. İnvaziv girişimlerde 24 saat, kanama riski yüksek ameliyatlarda ise en az 48 saat önce kesilmesi önerilmektedir. Kreatinin klerens $30 \mathrm{~mL} / \mathrm{dk}$. altında olan hastalarda cerrahiden 5 gün önce kesilmelidir ${ }^{[20]}$. Dabigatran ilk dozundan 4-6 saat önce epidural kateter çekilmelidir. Ciddi kanamalarda prokoagülan faktör VII kullanılabilir ${ }^{[20]}$.

Tablo 3. Antikoagülan kullanan yüksek trombotik riski bulunan olgularda preoperatif yönetim ${ }^{[11]}$.

\begin{tabular}{|c|c|c|c|c|}
\hline Preoperatif Gün -5 & Preoperatif Gün -4/-3 & Preoperatif Gün -2 & Preoperatif Gün -1 & Operasyon Günü \\
\hline $\begin{array}{l}\text { - Warfarin son dozu } \\
\text { alınır. }\end{array}$ & - Warfarin atlanır. & $\begin{array}{l}\text { - INR kontrolü } \\
\text { • Eger 2'den büyükse } 1 \mathrm{mg} \mathrm{K} \text { vit } \\
\text { oral verilir. -1 günde kontrol edilir. } \\
\text { • Eğer 1,5-2 arasında ise } 1 \mathrm{mg} \mathrm{K} \\
\text { vit oral verilir. } \\
\text { •-1 Günde kontrol edilir. Günde } \\
\text { iki kez deltaparin 100U kg_1 } \\
\text { - INR 1,5'ten düşük ise günde iki } \\
\text { kez dalteparin 100U kg_1 }\end{array}$ & $\begin{array}{l}\text { - -2.Günde INR 1,5'ten } \\
\text { büyük ise } 1 \mathrm{mg} \text { Vit K } \\
\text { • Son doz deltaparin 100U } \\
\text { kg_1 (cerrahiden } 24 \text { saat } \\
\text { önce) }\end{array}$ & $\begin{array}{l}\text { - } 1 \text {. Günde INR } 1,5 \text { 'ten } \\
\text { yüksek ise kontrol edilir. }\end{array}$ \\
\hline
\end{tabular}


Tablo 4. Antikoagülan kullanan yüksek trombotik riski bulunan olgularda postoperatif yönetim ${ }^{[11]}$.

\begin{tabular}{|c|c|c|c|c|c|c|}
\hline Operasyon Günü & $\begin{array}{l}\text { Postoperatif } \\
\text { Gün }+1\end{array}$ & $\begin{array}{l}\text { Postoperatif } \\
\text { Gün +2 }\end{array}$ & $\begin{array}{l}\text { Postoperatif } \\
\text { Gün }+3\end{array}$ & $\begin{array}{l}\text { Postoperatif } \\
\text { Gün }+4\end{array}$ & $\begin{array}{l}\text { Postoperatif } \\
\text { Gün }+5\end{array}$ & $\begin{array}{l}\text { Postoperatif } \\
\text { Gün }+6\end{array}$ \\
\hline $\begin{array}{l}\text { - Dalteparin dünde bir defa } \\
\text { kiloya uygun dozda }\end{array}$ & \multicolumn{2}{|c|}{ • Kullanılan Warfarin dozu } & \multicolumn{2}{|c|}{ • Kullanılan Warfarin dozu } & \multicolumn{2}{|c|}{ • Kullanılan Warfarin dozu } \\
\hline $\begin{array}{c}\text { - Postoperatif 6-8 saat sonra } \\
\text { başlanır }\end{array}$ & \multicolumn{2}{|c|}{ - Profilaktik Dalteparin } & \multicolumn{2}{|c|}{$\begin{array}{c}\text { - Dalteparin günde iki kez } \\
\text { uygulanır. }\end{array}$} & \multicolumn{2}{|c|}{$\begin{array}{l}\text { - INR 2'den yüksek olana } \\
\text { kadar devam edilir. } \\
\text { • Dalteparin günde iki kez } \\
\text { 100U kg uygulanır. }\end{array}$} \\
\hline
\end{tabular}

\section{C) Kalp cerrahisinde Postoperatif AF yönetimi}

Kalp cerrahisinde POAF sık görülen aritmidir. Morbiditeyi, hastanede kalış süresini uzatır ve maliyeti artırır. Koroner baypas cerrahisinden sonra \%40, kapak cerrahisi sonra $\% 64$ oranında ve cerrahiyi izleyen altı gün içinde $\mathrm{AF}$ gelişmektedir. AF riski hastaya, intraoperatif ve postoperatif olaylara bağlı olabilir. Hastaya bağlı faktörler ileri yaş, obezite, diyabet, hipertansiyon, atriyal dilatasyon ve sol ventrikül hipertrofisidir. İntraoperatif risk faktörleri arasında koroner baypas ve kapak cerrahisinin birlikteliği, sol atriyumun aşırı gerilmesi, pulmoner ven manüplasyonu sayılabilir. Postoperatif ise aşırı sıvı yüklenmesi, elektrolit bozukluklarında özellikle hipokalemi ve hipomagne- zemi ve inotropik ilaç desteği alan hastalar AF için riskli gruptur. Başlangıç semptomları, yeni başlayan taşikardi, çarpıntı, nefes darlığı ve hemodinamik stabilitenin bozulmasıdır. Kalp yetmezliği olan hastalarda yeni AF gelişimi hemodinamiyi bozabilir, aksine, kalp fonksiyonları normal olan birçok hastanın 150200 atım/dk. kalp hızına rağmen, hemodinamik verileri bozulmayabilir.

Tedavide elektrolit düzensizlikleri tedavi edilir, antiaritmik ilaç ve kardiyoversiyon uygulanır. Kardiyoversiyona düşük akım (50-100 j) ile başlamak miyokard hasarını en aza indirir, ancak 150-200 J uygulamanın daha başarılı olacağ belirtilmektedir $^{[11]}$ (Tablo 5).

Tablo 5. Postoperatif atriyal fibrilasyonda izlenecek yo[ ${ }^{[11]}$.

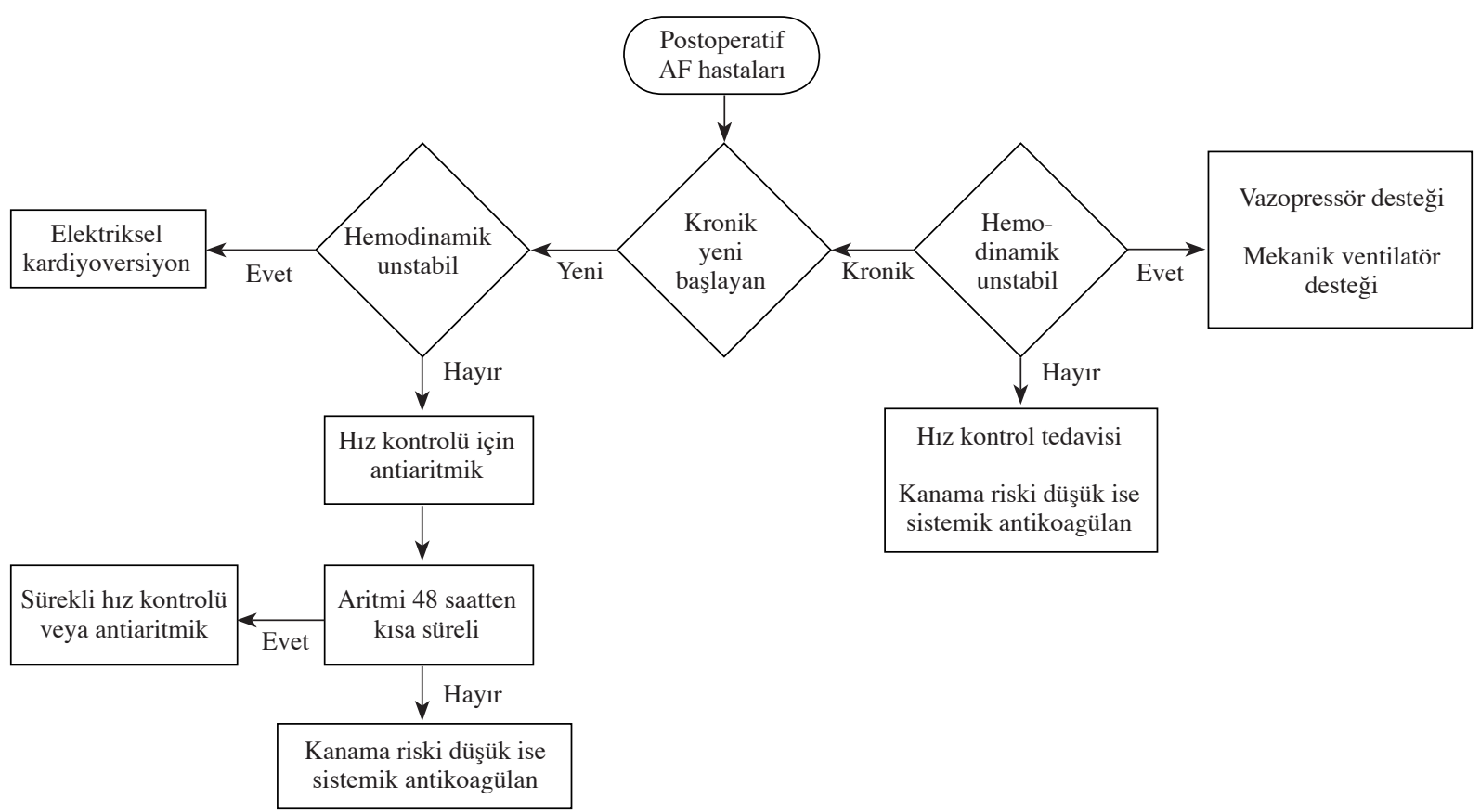




\section{D) Toraks ve özefagus cerrahisinde Postoperatif AF yönetimi}

Lobektomi, bilobektomi ve pnomonektomi sonrası hastaların dörtte birinde kardiyak aritmiler, özellikle supraventriküler aritmiler atriyal flatter, atriyal fibrilasyon ve supraventriküler taşikardiler görülür. $\mathrm{POAF}$ akciğer rezeksiyonundan sonra ikinci ve üçüncü günde en yaygındır. Yaygın akciğer rezeksiyonu, sağ akciğer girişimleri, geç dönem akciğer maligniteleri, eşlik eden periferik vasküler hastalıklar ve konjestif kalp yetmezliği ve aritmi öyküsü POAF gelişimi için risk faktörleridir. Postoperatif aritmilerin gerçek nedenleri bilinmemekle birlikte, adrenerjik ve vagal aktivite artış, atriyal dilatasyon ve inflamasyon, hiler diseksiyon, otonomik denervasyon, pulmoner hipertansiyon, sağ ventrikül dilatasyonu ve hipoksi katkıda bulunan faktörlerdir. POAF zararlı kabul edilmese de akciğer rezeksiyonlarında prognozu kötüleştirir ve hastanede kalış süresini ve mortaliteyi etkiler ${ }^{[21-24]}$. Akciğer rezeksiyonundan sonra AF oluşumunu önlemek için amiodarone, $\mathrm{MgSO}_{4}$, digoksin, ve $\mathrm{Ca}_{2}{ }^{+}$kanal blokerleri ile ilgili yapılan meta-analizde en etkili tedavinin amiodarone olduğu bildirilmiştir ${ }^{[21]}$.

\section{KRONIK ATRIYYAL FİBRILASYONU OLAN HASTALARIN KARDIYYOVERSIYON İSLEMINDE ANESTEZİ UYGULAMASI}

Kronik AF hastalarında kardiyoversiyon uygulaması derin sedasyon veya genel anestezi altında gerçekleştirilir. Kardiyoversiyonda sedasyon uygulanması, bu işlemin kısalığı, ağrılı olması nedeni ile özelliklidir. $\mathrm{Bu}$ hastalar mevcut kardiyak sorunları nedeni ile hemodinamileri stabil olmayan, akciğer sorunları nedeni ile de solunum depresyonuna yatkın hastalardır. Sedasyon dozunun ve seviyesinin ayarlanmsı önemlidir. Yetersiz sedasyon işlemin farkındalığını artırmakta, sempatik aktivite artışı özellikle yaşlı hastalarda tehlikeli ritm bozukluklarına neden olabilmektedir ${ }^{25-}$ 27]. Genel anestezi veya sedasyonun derinliğgini BIS monitorizasyonu ile değerlendirilebiliir ${ }^{[28-30]}$. Kabukcu ve ark.'nın ${ }^{[31]}$ çalışmasında, kronik AF tanısı alan hastalarda kardiyoversiyon için fentanil ve midazolam kombinasyonu ile Ramsay sedasyon skalası 5-6 düzeyinde bir sedasyon ile solunum ve hemodinamik stabilite sağlanmıştır. Özellikle deneyimi kısıtlı kişilerce verilecek sedasyonlarda anestezi derinliği ve ilaç dozunun belirlenmesinde BIS kullanımı önerilmiştir ${ }^{[1]}$.
Sonuç olarak, AF'lı hastaların anestezi yönetiminde; AF tanısı ve başlama zamanı, altta yatan nedenlerin tanınması ve düzeltilmesi gereklidir. Hemodinamik verilerin değerlendirilmesi, kardiyoversiyon uygulanması, ritm ve hız kontrolüne karar verilmesi, antikoagülan tedavinin yapılması ve düzenli olarak izlenmesi gerekmektedir.

\section{KAYNAKLAR}

1. Liao HR, Poon KS, Chen KB. Atrial fibrillation: an anesthesiologist's perspective. Acta Anaesthesiol Taiwan 2013;51:34-6.

https://doi.org/10.1016/j.aat.2013.03.010

2. Stewart S, Hart CL, Hole DJ, McMurray JJ. Population prevalence, incidence, and predictors of atrial fibrillation in the Renfrew/Paisley study. Heart 2001;86:516-21.

https://doi.org/10.1136/heart.86.5.516

3. Go AS, Hylek EM, Phillips KA, Chang Y, Henault LE, Selby JV, et al. Prevalence of diagnosed atrial fibrillation in adults: national implications for rhythm management and stroke prevention: the AnTicoagulation and Risk Factors in Atrial Fibrillation (ATRIA) Study. JAMA 2001;285:2370-5. https://doi.org/10.1001/jama.285.18.2370

4. Miyasaka Y, Barnes ME, Gersh BJ, Cha SS, Bailey KR, Abhayaratna WP, et al. Secular trends in incidence of atrial fibrillation in Olmsted County, Minnesota, 1980 to 2000, and implications on the projections for future prevalence. Circulation 2006;114:119-25. https://doi.org/10.1161/CIRCULATIONAHA.105.595140

5. Heeringa J, van der Kuip DA, Hofman A, Kors JA, van Herpen G, Stricker BH, et al. Prevalence, incidence and lifetime risk of atrial fibrillation: the Rotterdam study. Eur Heart J 2006;27:949-53. https://doi.org/10.1093/eurheartj/ehi825

6. Naccarelli GV, Varker H, Lin J, Schulman KL. Increasing prevalence of atrial fibrillation and flutter in the United States. Am J Cardiol 2009;104:1534-9. https://doi.org/10.1016/j.amjcard.2009.07.022

7. Lloyd-Jones DM, Wang TJ, Leip EP, Larson MG, Levy D, Vasan RS, et al. Lifetime risk for development of atrial fibrillation: the Framingham Heart Study. Circulation 2004;110:1042-6. https://doi.org/10.1161/01.CIR.0000140263.20897.42

8. Philip I, Berroëta C, Leblanc I. Perioperative challenges of atrial fibrillation. Curr Opin Anaesthesiol 2014;27:344-52. https://doi.org/10.1097/ACO.0000000000000070

9. Fuster V, Rydén LE, Cannom DS, Crijns HJ, Curtis AB, Ellenbogen KA, et al. 2011 ACCF/AHA/HRS focused updates incorporated into the ACC/AHA/ ESC 2006 guidelines for the management of patients with atrial fibrillation: a report of the American College of Cardiology Foundation/American Heart Association Task Force on practice guidelines. Circulation 2011;123:e269-367. https://doi.org/10.1161/CIR.0b013e318214876d

10. Hashemzadeh K, Dehdilani M, Dehdilani M. Postoperative atrial fibrillation following open cardiac sur- 
gery: predisposing factors and complications. J Cardiovasc Thorac Res 2013;5:101-7.

https://doi.org/10.5681/jcvtr.2013.022.

11. Raiten J, Patel PA, Gutsche J. Management of postoperative atrial fibrillation in cardiac surgery patients. Semin Cardiothorac Vasc Anesth 2015;19:122-9. https://doi.org/10.1177/1089253214551283

12. Schoonderwoerd BA, Smit MD, Pen L, Van Gelder IC. New risk factors for atrial fibrillation: causes of 'not-so-lone atrial fibrillation'. Europace 2008;10:66873.

https://doi.org/10.1093/europace/eun124

13. American Heart Association guidelines for cardiopulmonary resuscitation and emergency cardiovascular care. Circulation 2005;13:112(24 Suppl):IV1-203. https://doi.org/10.1161/CIRCULATIONAHA.105.166550

14. European Heart Rhythm Association, European Association for Cardio-Thoracic Surgery, Camm AJ, Kirchhof P, Lip GY, Schotten U, et al. Guidelines for the management of atrial fibrillation. Eur Heart $J$ 2010;31:2369-429. https://doi.org/10.1093/eurheartj/ehq278

15. Rogers WK, Schroeder KM. Perioperative atrial fibrillation and epidural anesthesia: case report and review of the literature. J Clin Anesth 2012;24:329-33. https://doi.org/10.1016/j.jclinane.2011.10.013

16. Aleksin AA, Khoronenko VÉ. Effects of prolonged thoracic epidural analgesia on the frequency of postoperative atrial fibrillation in thoracic surgery. Anesteziol Reanimatol 2014;59:10-4.

17. Bakhtiary F, Therapidis P, Dzemali O, Ak K, Ackermann H, Meininger D, et al. Impact of high thoracic epidural anesthesia on incidence of perioperative atrial fibrillation in off-pump coronary bypass grafting: a prospective randomized study. $J$ Thorac Cardiovasc Surg 2007;134(2):460-4.

https://doi.org/10.1016/j.jtcvs.2007.03.043

18. Benzon HT, Avram MJ, Green D, Bonow RO. New oral anticoagulants and regional anaesthesia. $\mathrm{Br} J$ Anaesth 2013;111 Suppl 1:i96-113. https://doi.org/10.1093/bja/aet401

19. van Veen JJ, Makris M. Management of peri-operative anti-thrombotic therapy. Anaesthesia 2015;70 Suppl 1:58-67.

https://doi.org/10.1111/anae.12900

20. Augoustides JG. Advances in anticoagulation: focus on dabigatran, an oral direct thrombin inhibitor. J Cardiothorac Vasc Anesth 2011;25:1208-12. https://doi.org/10.1053/j.jvca.2011.08.005

21. Zhang L, Gao S. Systematic review and meta-analysis of atrial fibrillation prophylaxis after lung surgery. $J$ Cardiovasc Pharmacol 2016;67:351-7. https://doi.org/10.1097/FJC.0000000000000351

22. Curtis JJ, Parker BM, Mckenney CA, WagnerMann CC, Walls JT, Demmy TL, et al. Incidence and predictors of supraventricular dysrhythmias after pulmonary resection. Ann Thorac Surg 1998;66:1766-71. https://doi.org/10.1016/S0003-4975(98)00942-4

23. Onaitis M, D'amico T, Zhao Y, O'Brien S, Harpole D. Risk factors for atrial fibrillation after lung cancer surgery: analysis of the society of thoracic surgeons general thoracic surgery database. Ann Thorac Surg 2010;90:368-74.

https://doi.org/10.1016/j.athoracsur.2010.03.100

24. Vaporciyan AA, Correa AM, Rice DC, Roth JA, Smythe WR, Swisher SG, et al. Risk factors associated with atrial fibrillation after noncardiac thoracic surgery: analysis of 2588 patients. J Thorac Cardiovasc Surg 2004;127:779-86.

https://doi.org/10.1016/j.jtcvs.2003.07.011

25. Stoneham MD. Anaesthesia for cardioversion. Anaesthesia 1996;51:565-70. https://doi.org/10.1111/j.1365-2044.1996.tb12566.x

26. Coll-Vinent B, Sala X, Fernández C, Bragulat E, Espinosa G, Miró O, et al. Sedation for cardioversion in the emergency department: analysis of effectiveness in four protocols. Ann Emerg Med 2003;42:767-72. https://doi.org/10.1016/S0196064403005109

27. Canessa R, Lema G, Urzúa J, Dagnino J, Concha M. Anesthesia for elective cardioversion: a comparison of four anesthetic agents. J Cardiothorac Vasc Anesth 1991;5:566-8. https://doi.org/10.1016/1053-0770(91)90007-G

28. Bowdle TA. Depth of anesthesia monitoring. Anesthesiol Clin 2006;24:793-822.

29. Avidan MS, Zhang L, Burnside BA, Finkel KJ, Searleman AC, Selvidge JA, et al. Anesthesia awareness and the bispectral index. N Engl J Med 2008;358:1097108. https://doi.org/10.1056/NEJMoa0707361

30. Johansen JW, Sebel PS. Development and clinical application of electroencephalographic bispectrum monitoring. Anesthesiology 2000;93:1336-44. https://doi.org/10.1097/00000542-200011000-00029

31. Kabukcu Karakaya H, Karakas MS, Yanikoglu A, Sahin N, Kabukcu M. Use of bispectral index monitoring for determination of sedation depth in 50 patients undergoing cardioversion. JPMA 2014;12:1370-4. WOS:000346551200009 